\title{
APLICAÇÃO DE CONCEITOS DA ENGENHARIA FORENSE NA ANÁLISE DE MANIFESTAÇÕES PATOLÓGICAS NA CONSTRUÇÃO CIVIL
}

\author{
BARRETO, GEOVANA \\ Estudante de Graduação de Eng. Civil. \\ Centro Universitário - UNITPAC. \\ Tocantins; Brasil. \\ eng.geovanabarreto@gmail.com \\ RÊGO, EMYLLE \\ Estudante de Graduação de Eng. Civil. \\ Centro Universitário - UNITPAC. \\ Tocantins, Brasil. \\ eng.emyllelopes@hotmail.com
}

\author{
FERNANDES, RENATO \\ Prof. Esp. do curso de Eng. Civil. \\ Centro Universitário - UNITPAC. \\ Tocantins, Brasil. \\ renato.fernandes@unitpac.edu.br \\ VASCONCELOS, ADRIANO \\ Prof. Me. do curso de Eng. Civil. \\ Centro Universitário - UNITPAC. \\ Tocantins, Brasil. \\ adriano.vasconcelos@unitpac.edu.br
}

\begin{abstract}
RESUMO
Manifestações patológicas são anomalias relacionadas à deterioração de edificações e a metodologia comumente usada no Brasil para analisar e identificar a causa dessas manifestações atua de acordo com os sinais expostos de alterações anormais no local, no qual espera-se encontrar os sintomas mais habituais que acarretem em uma patologia conhecida. Entretanto, percebeu-se que estes métodos que outrora eram uma tecnologia avançada de reconhecimento podem ser substituídos por técnicas mais completas, por isto, este artigo tem o intuito de apresentar e adaptar ao contexto brasileiro as metodologias de diagnóstico criadas por pesquisadores da Universidade de Delft, na cidade de Delft/Países Baixos. Esta metodologia conta com três técnicas de Engenharia Forense: Investigation Steps (Etapas da Investigação), The Life-Cycle (O Ciclo de Vida) e The Tree of Failures (A Árvore de Falhas), que devem ser utilizadas de forma unificada para que se encontre a causa raiz de um problema. Como esta metodologia foi criada para ser utilizada de forma genérica em diversas áreas e contextos, este artigo têm a função de refinar estas técnicas e demonstrar como utilizá-las no campo das patologias na construção civil nacional. Para tal, fez-se um estudo de caso que ratificou sua eficácia, onde foi possível diagnosticar as causas das manifestações patológicas existentes em um prédio público na cidade de Araguaína- TO, que foram originadas devido a erros na confecção dos elementos estruturais, como excesso de agregados na dosagem do concreto, má disposição dos estribos e o cobrimento abaixo do mínimo exigido por norma. Palavras-Chave: diagnóstico, engenharia forense, patologia.
\end{abstract}

\section{ABSTRACT}

Pathological manifestations are anomalies related to deterioration of buildings, and the methodology commonly used in Brazil to analyze and identify the cause of these pathologies acts according to the exposed signs of abnormal changes in the site, which is expected to find the most common symptoms that cause a known pathology. However, it was realized that these methods were once an advanced recognition technology can be replaced by more complete techniques, so this article aims to present and adapt to the Brazilian context the diagnostic methodologies created by researchers at Delft University, in the city of Delft/ Netherlands. This methodology has three Forensic Engineering techniques: Investigation Steps, The Life-Cycle and The Tree of Failures, which should be used in a unified way to find the root cause of the problem. To this end, a case study was made that confirmed its effectiveness, where it was possible to diagnose existing failures in a public building in the city of Araguaína-TO due to errors in the fabrication of structural elements, such as excess of aggregate in concrete dosing, stirrups misplacement and coverage below the minimum required by norm.

Keywords: diagnosis, forensic engineering, pathology.

\section{INTRODUÇÃO}

A área da construção civil demonstra grandes avanços tecnológicos desde os primórdios da humanidade, o que proporcionou ao homem conhecimento e habilidades o suficiente para projetar edificações. Entretanto, em todas as épocas existiram casos das edificações não apresentarem o comportamento esperado quanto à durabilidade da 
construção. Já que durante a vida útil de um edifício é possível que ocorram falhas de desempenho, que podem originarse por erro de projeto, de execução ou acidentais, isto é conhecido como manifestação patológica.

Os problemas que contribuem para a degradação das construções decorrem de muitos fatores distintos. Com muita frequência as causas de determinados problemas não são facilmente detectadas, ou podem ainda estar associadas a outras falhas, induzindo assim a erros de diagnósticos. Por isto, de acordo com Stimson (2018), a principal característica que um engenheiro civil que trabalha com investigações precisa possuir é a capacidade de identificar falhas e coletar informações do local em que elas aconteceram para posterior análise em laboratório.

A engenharia forense ou de perícia existe justamente para responder a questões que geralmente possuem demasiada dificuldade em serem respondidas e que estão associadas à degradação, acidentes, crimes e eventos catastróficos. Ela é uma forma de reunir e aplicar princípios e metodologias de engenharia, onde, a partir deste ponto de partida, o investigador forense coleta evidências para fazer a "engenharia reversa" de como uma falha ocorreu; onde ele procura determinar: Quem? O quê? Onde? Quando? Por quê? E como? (NOON, 2001).

Para auxiliar e guiar engenheiros forenses, os professores da TU Delft (Universidade de Tecnologia de Delft) formularam em 2018 um sistema de análise baseado em teorias pré-estabelecidas pela literatura com as melhores práticas de investigação. Este sistema tem um procedimento lógico a ser seguido, com passos e processos definidos que ajudam o engenheiro a ter a garantia de que a análise das patologias foi executada corretamente.

Por ser uma metodologia complexa, genérica e de origem estrangeira, o objetivo deste trabalho foi adaptá-la ao contexto brasileiro nos diversos cenários de manifestações patológicas, de forma que a investigação forense seja feita sistematicamente e com o intuito de descobrir se estas técnicas inovadoras da TU Delft serão eficazes neste caso. Este método foi escolhido porque é sabido que diagnosticar corretamente uma falha, sem a utilização de uma metodologia eficiente é uma tarefa complexa, advinda pela dificuldade em relacionar a coexistência de vários fatores que podem gerar diferentes manifestações patológicas que por diversas vezes mutuamente se unem e podem dificultar a investigação patológica.

\section{FUNDAMENTAÇÃO TEÓRICA}

\subsection{Patologia e manifestações patológicas}

De acordo com Deutsch (2013) patologia é o estudo das manifestações patológicas relacionadas à deterioração das edificações, que são as insuficiências funcionais e/ou estruturais que podem ser originadas devido a falhas nos sistemas ou nos elementos que o compõem. Já a falha de um sistema técnico pode ser definida como um estado ou condição em que este sistema específico não pode cumprir de forma mensurável algumas ou quaisquer das suas funções previstas. As manifestações patológicas podem ocorrer de diferentes formas, entre elas: trincas, fissuras, infiltrações e danos por umidade excessiva. Elas são uma expressão resultante de mecanismos de degradação, aos quais as edificações estão expostas (ENAMI, 2010).

\subsection{Vida útil e vida útil de projeto}

Em uma edificação as manifestações patológicas costumam ser visíveis ao fim da vida útil, porém, existem ainda edificações que apresentam falhas antes da finalização deste prazo, devido a diversos fatores que podem ir desde o projeto, a execução ou por negligência na manutenção. A ABNT (NBR 15575-1: 2013) determina como vida útil (VU) a medida temporal de durabilidade que cada elemento que compõe a estrutura deve desempenhar na função para a qual foi atribuido.

Esta mesma norma define vida útil de projeto (VUP), como o prazo estimado de tempo em que um sistema é projetado a fim de satisfazer aos requisitos de desempenho estabelecidos. A VUP de cada sistema deve ser descrita no projeto, ela é determinada após uma estimativa teórica que pode ser comprovada ou não. Além disso, esta norma também define que cabe ao construtor ou ao incorporador elaborar o manual de operação, uso e manutenção, que quando aplicado a unidades autônomas é chamado de manual do proprietário. 


\subsection{Metodologias de diagnóstico existentes no contexto brasileiro}

Percebe-se que o estudo dos problemas patológicos nas edificações tornou-se necessário no contexto atual, perante este fato, foram desenvolvidas metodologias sistemáticas para auxiliar na obtenção de informações sobre cada falha. Segundo Helene (2002), a identificação das manifestações patológicas e as medidas terapêuticas que devem incidir sobre o local, podem ser organizadas de forma sistemática para acelerar o processo de definição da conduta terapêutica. Seguindo este pensamento, o autor apresenta um método de investigação tradicional, bastante utilizado.

Ainda segundo o autor, estas metodologias trazem consigo o objetivo de determinar a origem da falha de acordo com os sinais que a edificação apresenta, desta maneira, ao descrever os sintomas mais habituais nas construções, pode-se verificar como cada uma delas acarretará em uma manifestação patológica conhecida. O método é seguido por etapas, através da identificação das falhas. Ao responder as perguntas contidas na figura 1 é possível avançar ou retornar no diagrama, até que se obtenha um diagnóstico. Em seguida, é definido o tipo de terapia e como deverá ser executada. Por fim, faz-se uma última avaliação do local, garantindo a viabilidade do projeto de reparo executado e registrando o caso.

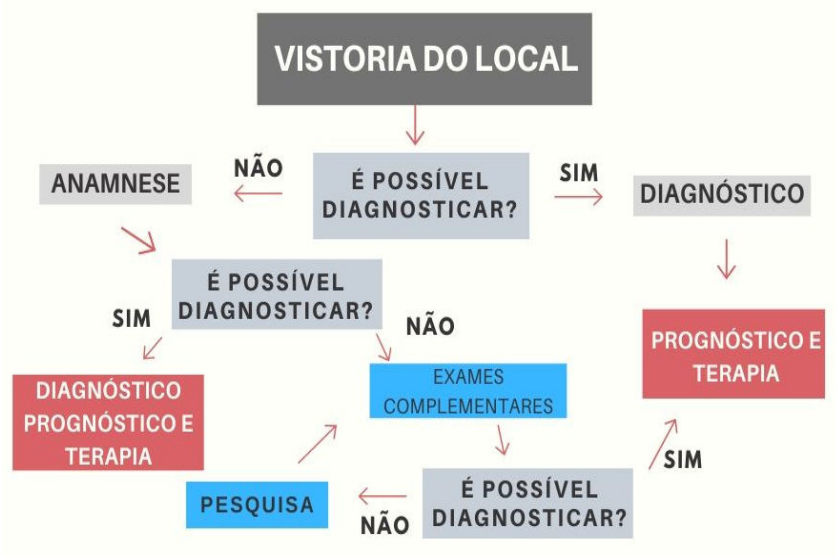

Figura 1: Método de investigação patológica tradicional. Fonte: Adaptado de Helene (2002).

Normalmente, quem aplica esta metodologia convencional são engenheiros que já têm um amplo conhecimento a respeito dos problemas que podem vir a ocorrer em uma edificação, com isto, percebe-se que para obter resultados deste diagrama requer certa experiência. Diante da realidade exposta sobre a metodologia nacional, é oportuno que se estude outras metodologias que venham facilitar o processo de análises patológicas.

Dentre os diversos procedimentos existentes no mundo, pode-se destacar a metodologia forense da TU Delft, uma vez que ela coopera para a qualidade do trabalho do profissional, visto que possibilitam a sistematização do problema para a verificação de todas as suas possibilidades, dando maior confiabilidade ao resultado encontrado.

\subsection{Engenharia Forense}

De acordo com as afirmativas do autor Noon (2001) a Engenharia Forense pode ser definida como a prática profissional de determinar a causa, ou causas, da ocorrência de falhas em um sistema técnico. Segundo o mesmo autor esta técnica consiste na aplicação de princípios e metodologias que buscam soluções em ocorrências de incidentes, onde é necessária uma visão especializada para se chegar as causas do ocorrido. Com isto é possível notar a correlação entre a engenharia forense e as manifestações patológicas, já que como foi dito anteriormente estas manifestações podem ser causadas por falhas nos sistemas técnicos.

\subsection{Metodologia de diagnóstico Tu Delft}

Esta abordagem da Universidade Tecnológica de Delft integra três elementos de engenharia forense, que foram adaptados pelos autores para serem utilizados no campo da investigação patológica, de modo que se adequem o máximo 
possível ao proposto. A primeira técnica é o Investigation Steps (Etapas da Investigação), que é um sistema investigativo com etapas criadas para organizar o processo forense.

O segundo elemento é o The Life-Cycle (O Ciclo de Vida), dado que uma construção tem um ciclo de vida com várias fases é importante considerar estas fases quando a falha é investigada. Em sequência, o terceiro termo é a The Tree of Failures (A Árvore de Falhas), já que reconhecer uma falha é um fenômeno multifacetado, esta metodologia aborda a categorização das causas de falhas que podem ser relacionadas ao problema em questão.

\subsubsection{Investigation Steps}

Para realizar uma investigação sistemática é essencial ter um processo definido. Por isto, na análise das etapas de investigação a abordagem Delft formulou os seguintes passos para serem seguidos pelos engenheiros forenses: orientação, coleta de dados, geração e teste de hipóteses, relatório de descobertas e de recomendações. A fase da orientação tem como objetivo descobrir quem é a parte mais interessada na investigação, quem está envolvido, quem pode estar relacionado com a causa e qual a estratégia que vai ser utilizada para coletar informações (STIMSON, 2018).

A coleta de dados é dividida em duas partes; na primeira acontecerá a investigação de campo onde é preciso anotar o local onde ocorreu o problema, pegar depoimentos das pessoas que estavam lá e tirar fotos deste local. A segunda parte desta fase realiza-se em escritório, nesse momento é necessário pesquisar em um banco de dados por relatórios de eventos similares, analisar o ciclo da vida e relacionar com o sistema da árvore de falha, que são descritos posteriormente (TERWEL; SCHUURMAN; LOEVE, 2018).

Durante a geração de hipóteses, o investigador deve fazer uma lista de possíveis explicações para o que pode ter causado o início da falha, sempre seguindo uma sequência de eventos. Esta sequência deve passar por testes, para que a hipótese mais lógica seja encontrada.

Dessa maneira, depois de desenvolvida as hipóteses devem-se reportar as informações adquiridas, o que consiste em fazer um relatório com todas as respostas encontradas durante a investigação, além disso, em uma investigação íntegra as recomendações e dicas aprendidas devem ser escritas no laudo com o intuito de ajudar a identificar falhas semelhantes no futuro (KARDON, 2012).

\subsubsection{The Life Cycle}

De acordo com Ferreira (2014), o ciclo de vida compreende todas as transformações pelos quais os seres humanos, sistemas ou objetos podem sofrer durante a sua vida. No contexto da análise forense Terwel, Schuurman e Loeve (2018) afirmam que o estudo do ciclo da vida possui características específicas, por isto não consiste apenas na investigação generalizada da execução, ela engloba todos os elementos constituintes, ou seja, a análise é realizada desde o tipo de matéria prima utilizada para a fabricação dos elementos estruturais, as manutenções realizadas na edificação, até o fim da sua vida útil.

Este método exibe as várias fases do ciclo de vida de uma construção. Essas fases são divididas em:

1. Desenvolvimento: fase onde o sistema técnico é planejado e projetado, além disso, os materiais a serem utilizados são escolhidos;

2. Produção: fase da fabricação e montagem, ou seja, execução do projeto e montagem dos elementos constituintes;

3. Utilização: período de uso em que é necessário realizar manutenções e reparos;

4. Reciclagem: quando o produto chega ao fim da sua vida útil e é necessário ser reciclado ou descartado.

\subsubsection{The Tree of Failures}

Esta etapa da investigação é constituída por um sistema dedutivo, em que as análises dos eventos ocorrem de cima para baixo, o que permite a visualização das interdependências entre os componentes e a identificação de quais conjuntos de fatores pode levar ao evento indesejado, ou seja, a falha que aconteceu. O intuito dessa metodologia é ajudar a encontrar a causa da falha que ocorreu ao usar o pensamento reverso. Esta árvore de falhas é constituída por três conjuntos de "galhos de falhas" que são as falhas gerais. Cada um destes galhos cresce em cima das "raízes causais", estas são as prováveis causas raízes do problema. 
A Árvore de Falhas é apresentada na figura 2 de forma sistemática, ela é composta na parte superior por três grupos principais de falhas, que são: produto, instrução e execução. Cada um destes possui várias falhas de modo geral, decorrentes dos problemas que podem ocorrer. Por fim, as falhas inferiores, que são representadas pelas raízes, são as características mais específicas de todo o conjunto (TERWEL; SCHUURMAN; LOEVE, 2018).

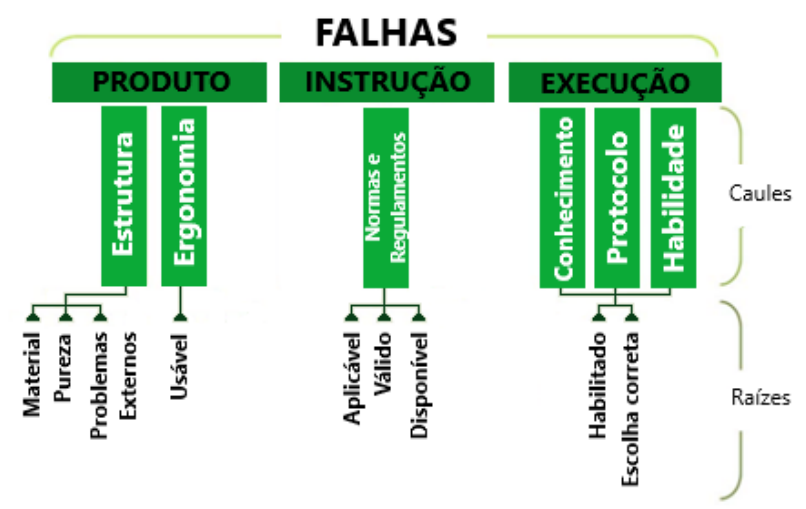

Figura 2: Árvore de Falhas Completa.

Fonte: Adaptado de Terwel, Schuurman e Loeve (2018).

Todas as etapas devem ser detalhadas da seguinte forma: os galhos relacionados a falha geral produto são: estrutura e ergonomia. Em se tratando da estrutura, devem-se investigar os problemas decorrentes de falhas na integridade física da construção, como aspectos relacionados ao material utilizado, da sua pureza e de problemas externos a edificação. No caso da ergonomia, é necessário examinar problemas decorrentes de como a configuração do sistema técnico é fácil de ser usada e mantida.

Seguindo a afirmativa dos autores Terwel, Schuurman e Loeve (2018), para falhas na estrutura, têm-se três raízes: material, pureza e problemas externos. A raiz material engloba a configuração e a geometria, onde a configuração do sistema técnico deve ser analisada para verificar se o procedimento estava completo e bem montado, a geometria de quaisquer partes potencialmente envolvidas na falha deve ser averiguada para constatar se houve algum erro devido à forma ou tamanho dos elementos constituintes.

Em seguida, a pureza entende-se como não ter nada no sistema técnico que não deveria estar lá, ou seja, a alteração incomum de qualquer parte do sistema técnico pode também ser a consequência de uma falha. A raiz problemas externos é sobre questões decorrentes de conexões com o ambiente em que foi executada a construção, da qual toda a estrutura depende (TERWEL; SCHUURMAN; LOEVE, 2018). Desta maneira, para o termo ergonomia, têm-se a raiz usável, o termo indica o quão explícito está ou quão fácil é aprender como o sistema técnico deve ser usado e o que o usuário deve fazer para mantê-lo em boas condições de uso, ou seja, pode ocorrer uma falha através do uso inadequado.

Em sequência, as causas relacionadas à instrução devem descrever como o sistema é projetado, produzido, utilizado ou reciclado. A raíz neste portador de falha refere-se a instruções provenientes de normas e regulamentos (NR's e NBR's). As normas e regulamentos são instruções emitidas que garantem a integridade e segurança da construção, por isto, deve-se ficar atento se estas foram respeitadas por todos. Nelas estão contidas informações como o tipo e quantidade de material que deve ser utilizado para adquirir resistências mínimas necessárias e a metodologia que deve ser executada para que se possa obter o produto desejado.

Terwel, Schuurman e Loeve (2018) afirmam que este ramo da instrução acarreta nas falhas: aplicável, válido e disponível. Com relação à aplicabilidade, é preciso procurar esclarecer se os requisitos do projeto foram utilizados corretamente. A validade tem função de informar se as instruções apropriadas levaram a resultados concretos, ou seja, a validação do projeto. Enquanto isso, a raiz disponibilidade busca investigar se o material necessário para a execução correta do projeto estava disponível e se este foi utilizado.

As causas relacionadas à execução analisam se todas as instruções prescritas foram realmente executadas em todas as fases do ciclo de vida. Os erros mais específicos decorrentes desta etapa são devido à falta de: conhecimento, protocolo 
e/ou habilidade. Existem duas raízes que carregam as falhas superiores a elas. Estes são: habilitado e escolha correta. Ou seja, todas as falhas decorrentes da execução dizem respeito da capacidade do executor. A falha poderia acontecer na escolha, que é sobre a tomada de decisão e na capacitação que é sobre o quão bem a parte envolvida tem conhecimento e habilidade de fazer as escolhas certas ou realizar adequadamente quaisquer ações.

O digrama da Árvore de Falhas consiste no método mais sistemático e complexo dentre os três apresentados, uma vez que este possui etapas detalhadas em que é necessário verificar cada uma das possíveis causas do problema, respondendo perguntas diretas como: a falha ocorreu no produto, nas instruções de aplicação deste produto ou na execução? Este método, associado com o do Ciclo da Vida, formam uma rotina de exploração de falhas, que são as Etapas da Investigação, o que permite descobrir as causas potenciais de falha com uma maior assertividade, quando comparado a outros métodos convencionais de investigação patológica (TERWEL; SCHUURMAN; LOEVE, 2018).

\section{METODOLOGIA}

O presente artigo é classificado como uma pesquisa científica aplicada, haja vista que se trata de uma nova metodologia que foi adaptada para o contexto de patologia na construção civil brasileira empregando evidências empíricas, ratificado através de uma pesquisa de campo. Quanto aos objetivos caracteriza-se como exploratório, sendo uma pesquisa quantitativo-qualitativa no que diz respeito à abordagem metodológica e, por fim, quanto aos procedimentos, classificam-se como uma pesquisa bibliográfica seguida de estudo de caso (MARCONI; LAKATOS, 2002).

Este trabalho avaliou as manifestações patológicas existentes em um prédio público da cidade de Araguaína/TO, com enfoque nos elementos estruturais do local, onde foi analisado o ciclo de vida da edificação, com a finalidade de criar hipóteses através da árvore de falhas e diagnosticar as anomalias presentes nesse local, seguindo as etapas da investigação, em que foi concebido o laudo com as recomendações.

Inicialmente foi efetuada a pesquisa bibliográfica, ampliando os conhecimentos sobre o assunto abordado, em seguida executado o estudo de caso para ratificar o tema. O estudo de caso foi dividido em fases, que são as mesmas etapas da investigação: orientação, coleta de dados, geração de hipóteses, teste de hipóteses, relatório de descobertas e recomendações. Onde a orientação e a coleta de dados são analisadas juntamente com o Ciclo de Vida da estrutura do edifício, a geração e o teste de hipóteses são realizados na Árvore de Falhas e finalmente o relatório de descobertas e recomendações são gerados em conjunto.

$\mathrm{Na}$ orientação precisou-se analisar o intuito do prédio, como ele é utilizado, quem são os principais responsáveis pela sua manutenção. Em sequência, houve a coleta dos dados, onde o objetivo principal foi a coleta de toda e/ou qualquer informação relevante, que agregava conhecimento sobre o evento patológico. Em decorrência disto, a coleta de dados ocorreu primeiramente com a investigação de campo, ao analisar o local, recolher informações das pessoas que estavam presentes, além, da realização de registros fotográficos. Por fim, foi realizada a etapa da geração de hipóteses, seguindo o sistema metodológico descrito pela árvore de falhas.

As hipóteses geradas foram dispostas em um quadro, que está no apêndice A, em seguida foi dado continuidade na investigação através de testes para verificar as hipóteses planejadas e o quão elas são viáveis. Após testar todas as hipóteses, foi preenchido e posteriormente redigiu-se o relatório descrevendo a falha e a sua origem e, por fim o laudo com recomendações foi gerado.

\subsection{Estudo de Caso}

O estudo de caso foi realizado em um prédio público localizado na Rua Humberto de Campos, esquina com a Avenida Primeiro de Janeiro, $\mathrm{n}^{\mathrm{o}}$ 508, bairro São João, na cidade de Araguaína- TO. A figura 3 indica a posição geográfica da edificação. As manutenções dele são de responsabilidade da prefeitura da cidade. 


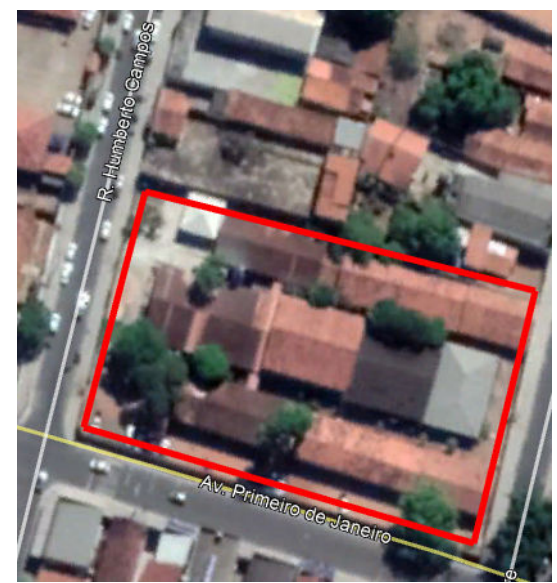

Figura 3: Posição geográfica do local de estudo.

Fonte: Autoras (2019).

\subsubsection{Análise do Ciclo de Vida}

Nesta etapa foi analisado o ciclo de vida da edificação, de modo a indicar em que etapa se encontra atualmente e também destacar, caso seja cabível, como a edificação perpassou pelos demais períodos do ciclo de vida. Ao chegar ao local logo se percebeu que a edificação está na fase de utilização, este é o período de uso em que é necessário realizar manutenções e reparos com periodicidade. Notou-se também que o prédio é antigo e conta com uma grande circulação de pessoas. Os usuários do prédio afirmaram que ele tem cerca de 32 anos.

Como o intuito é de analisar apenas a parte estrutural do prédio estudado, verificou-se no ciclo de vida (primeira etapa) uma peculiaridade nos agregados, já que foi possível perceber uma quantidade exagerada deles na composição do agregado, como mostra a figura 4 que é uma foto de um pilar que está sofrendo um processo de desagregação do concreto.

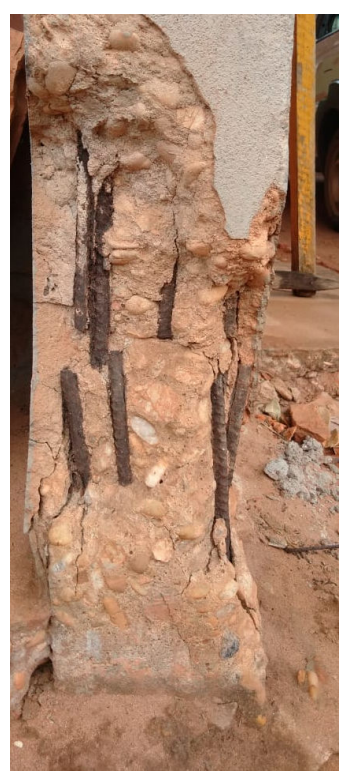

Figura 4: Pilar em processo de desagregação.

Fonte: Autoras (2019).

O projeto executado seguiu a norma ABNT (NBR 6118: 1978), que era vigente na época. Entretanto, existiram modificações desde esta norma, como por exemplo, os procedimentos relacionados a durabilidade com intuito de garantir a qualidade das estruturas de concreto que foram introduzidas pela ABNT (NBR 6118: 2007), onde pela primeira vez foi relacionada as condições de exposição da estrutura, conhecida como classe de agressividade ambiental, 
com os valores mínimos característicos de resistência que devem ser respeitados, o valor mínimo do cobrimento da armadura e na máxima abertura de fissura permitida.

Desta forma, desde o ano do lançamento da norma todas as manutenções posteriores deveriam ter acontecido adequando o prédio aos valores mínimos exigidos em norma, ao menos nos locais críticos onde houve grande perda na massa de concreto. Isto posto, a segunda etapa deste Ciclo diz respeito à realização da construção, onde notou-se que em alguns lugares o cobrimento foi executado de forma incorreta, sem respeitar o cobrimento mínimo da armadura descrito na ABNT (NBR 6118: 2014).

Logo, é compreensível que em 1987, quando o edifício foi construído, os executores não tenham seguido a norma de 2007, quando pela primeira vez foi apresentado os valores recomendáveis de cobrimento, entretanto é repreensível que as manutenções tenham sido realizadas sem se atentar aos aprimoramentos, nos locais críticos de perda de concreto, que deveriam ter sido feitas para atender ao menos os cobrimentos mínimos que foram adotados. Na figura 5 nota-se que o cobrimento utilizado não tem espessura mínima necessária para proteger a armadura.

A respeito da terceira etapa, que se trata da manutenção do prédio, ela tem a função de corrigir problemas causados por manifestações patológicas ao mesmo tempo em que adequa o prédio. A ABNT (NBR 15575: 2013) afirma que nos projetos é necessário que se tenha especificado valores teóricos para a VUP de cada um dos sistemas, estes valores não podem ser inferiores aos estabelecidos por ela, a qual determina que a estrutura deve ter uma VUP mínima de 50 anos, este critério foi estipulado de acordo a ABNT (NBR 8681: 2004).

Entretanto, diversos especialistas afirmam que um prédio deve durar entre 50 a 100 anos; está variação acontece seguindo o Ciclo de Vida, ou seja, depende de como este edifício foi construído, como é utilizado e, o mais importante, como ele é mantido. Por isto, a ABNT (NBR 5674: 2012) estabelece requisitos que devem ser seguidos na manutenção dos edifícios. O prédio estudado passou por diversas reformas que não seguiram esta norma, já que é possível notar que estas reformas tinham um intuito apenas estético, ou seja, só foram realizados repinturas, mesmo que por cima da armadura exposta, como mostra a figura 6.

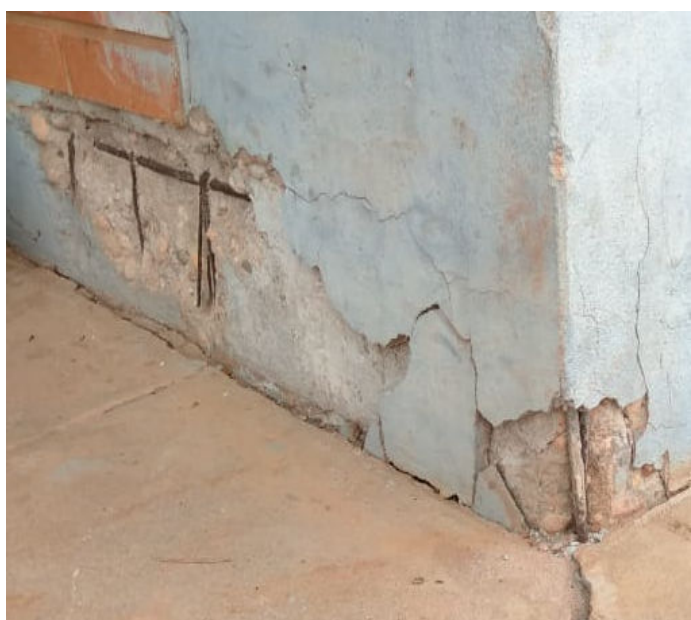

Figura 5: Foto de armadura exposta. Fonte: Autoras (2019).

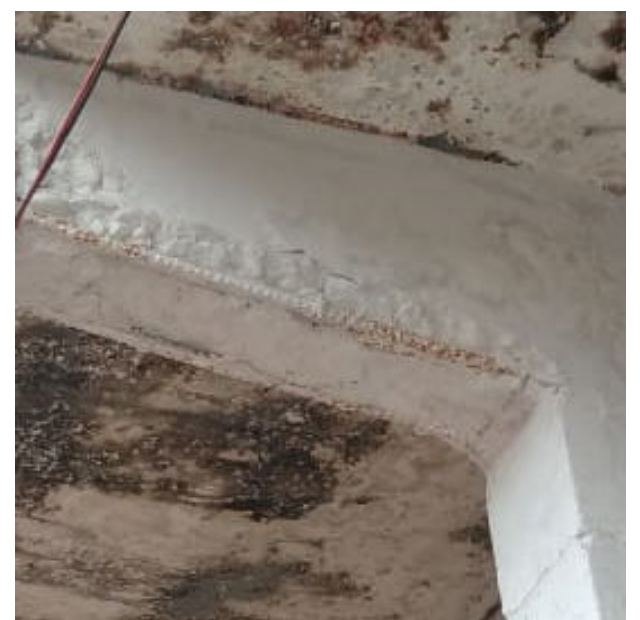

Figura 6: Foto de uma viga com armadura exposta. Fonte: Autoras (2019).

\subsubsection{Análise da Árvore de Falhas}

De acordo com o que foi apresentado na fundamentação teórica, a árvore de falhas deve ser feita a partir de caules e raízes que foram previamente definidos, para cada uma das raízes deve ser gerada pelo menos uma hipótese razoável. Essas hipóteses foram feitas de acordo com as patologias encontradas.

A falha Produto contém dois caules causais, sendo eles Estrutura e Ergonomia. A estrutura divide-se em três raízes causais: o primeiro é o material, que abrange todos os problemas relacionados com a matéria prima utilizada, neste 
deve-se procurar criar hipóteses de que a falha tenha ocorrido por decorrência do tipo de material escolhido, como por exemplo, a escolha do cimento, do agregado e da bitola do aço.

A segunda raiz do caule estrutura é a pureza, que indica as falhas que podem ocorrer devido a impurezas, ou seja, a presença de algo que não deveria existir naquele local, como por exemplo, a existência de elementos orgânicos na água de amassamento. Já a terceira raiz que são os problemas externos está mais relacionada com a situação em que se encontrava o ambiente externo na época da execução da construção e em como este fator pode ter afetado negativamente a edificação.

O segundo caule do Produto é a ergonomia e a sua raiz causal é ser usável, logo, a hipótese gerada deve ser relacionada a falta de usabilidade do edifício, como a falta de instrução para realizar manutenções, por exemplo. Os caules e raízes pré-definidos pela metodologia TU Delft, com adaptações, para a falha devido ao produto são mostrados na figura 7.

Em sequência, a falha Instrução tem como caule causal as normas e regulamentos, de onde surgem as três raízes causais. A primeira é sobre a aplicabilidade, o segundo é sobre a validez da instrução e o terceiro é relacionado com a falta de disponibilidade desta instrução. Os elementos pré-definidos para a falha instrução podem ser vistos na figura 8.

$\mathrm{Na}$ falha Execução, os caules conhecimento, protocolo e habilidade são interligados, os três têm raízes causais ligados a habilidade ou escolha correta. Na raiz causal, a hipótese deve ser relacionada a falta de capacidade ou conhecimento do executor do projeto; já a segunda raiz causal escolha certa deve ser relacionada a hipótese do engenheiro projetista ou do construtor de terem feito algum tipo de escolha incorreta, mesmo que sem querer. A falha execução e seus segmentos podem ser vistos na figura 9.

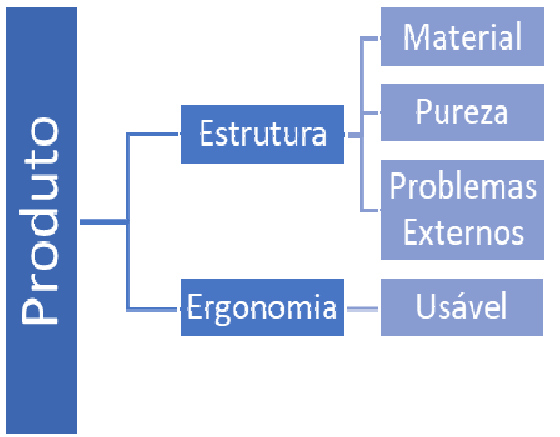

Figura 7: Falha produto. Fonte: Adaptado de Terwel, Schuurman e Loeve, (2018).

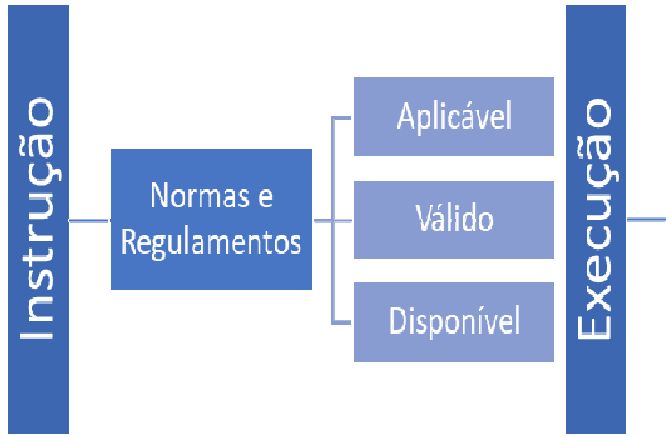

Figura 8: Falha Instrução. Fonte: Adaptado de Terwel, Schuurman e Loeve, (2018).

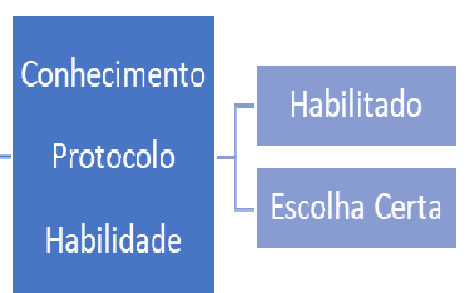

Figura 9: Falha Execução. Fonte: Adaptado de Terwel, Schuurman e Loeve, (2018).

\subsubsection{Elaboração do Laudo}

A última fase da metodologia consiste na elaboração do laudo técnico e das recomendações, que devem mostrar de forma objetiva, impessoal e completa como a investigação foi realizada, os dados que foram levados em consideração, as conclusões e as recomendações. Além disso, é importante que este laudo seja realizado de acordo com a norma ABNT (NBR 14653: 2019).

Por fim, após obter todas as respostas, o laudo patológico da edificação é gerado, contendo as falhas identificadas, relatos fotográficos e depoimentos confiáveis. Possuindo também recomendações fundamentais das causas das manifestações patológicas, podendo conter também informações de como prosseguir com o reparo da estrutura do edifício.

\section{RESULTADOS E DISCUSSÃO}

O estudo de caso foi iniciado no mês de agosto do ano de 2019, quando os dados foram coletados e os registros fotográficos foram feitos. Durante as visitas realizadas foram identificadas patologias estruturais visíveis no local, desta maneira, foi dado ênfase neste tipo de falha e aplicado a metodologia proposta. 
No decorrer do estudo de caso foi identificado que as partes interessadas pela investigação patológica são as unidades responsáveis do edifício, sendo elas o governo estadual que é proprietário da edificação e a prefeitura de Araguaína que utiliza o local atualmente, por isso, trata-se de um prédio conveniado.

Com as informações adquiridas, foi aplicada a análise do ciclo de vida na edificação identificando que a mesma possui mais de 32 anos e está na fase de utilização, período este em que é necessário fazer manutenções e reparos.

Através da visita ao local, foi possível identificar falhas na confecção dos elementos estruturais e que os mesmos não foram beneficiados com as manutenções ocorridas posteriormente, pois as manutenções atentavam-se apenas a patologias de umidade, retirando goteiras e repintando locais onde a pintura estava desgastada, não beneficiando os elementos estruturais que necessitam de reparo. Há locais em que a armadura destes elementos estruturais está exposta e existe perda de seção de concreto.

Logo depois, com a análise da Árvore de Falhas, mais especificamente nas falhas decorrente do Produto percebe-se que o caule estrutura contém três raízes causais, onde a primeira é o Material e a hipótese que foi gerada sobre ele é relacionado à má disposição dos estribos nas vigas e pilares, esta hipótese se enquadra na raiz material porque neste caso as vigas e os pilares são os materiais que compõe o produto analisado que é a própria estrutura de concreto. Já a segunda raiz, pureza, tem como hipótese a impureza nos agregados que pode vir a diminuir a resistência do concreto e a terceira raiz, problemas externos, não se aplica a este caso, pois ela está ligada diretamente a fase de execução do projeto e infelizmente não foi possível obter informações da época da construção da edificação.

O segundo caule do Produto é a Ergonomia e a sua raiz causal é a usabilidade, a hipótese gerada é que não houve um manual de como usar e realizar manutenções no local, como é recomendado pela ABNT (NBR 15575: 2013) que descreve a necessidade de que o construtor crie um manual de operação, uso e manutenções do edifício, e por isso é possível que esta falta tenha comprometido as manutenções que foram realizadas posteriormente.

Em sequência, a falha Instrução tem como caule causal as Normas e Regulamentos, e três raízes causais. A primeira é aplicável, onde não foi gerada hipótese, pois para isto seria necessário o projeto original; a segunda refere-se a validade dessas normas, onde a hipótese é que os dados eram inexistentes na norma vigente no período de construção do prédio, onde a ABNT (NBR 6118: 1978) não especificava os valores mínimos de cobrimento; a terceira é relacionado com a falta de disponibilidade de informações na época, nesta mesma norma, a respeito da relação água/cimento para se atingir a resistência necessária.

Na raiz causal habilidade a hipótese é que os reparos foram realizados com cunho apenas estético e sem responsável técnico; a segunda raiz causal está relacionada com o erro na quantidade de agregados, que foi exagerada na dosagem do concreto, acarretando em ninhos de concretagem. O motivo lógico para cada uma das hipóteses geradas pode ser visto detalhadamente no apêndice A.

Através dos registros fotográficos gerados pode-se perceber que determinados pilares necessitam de manutenção urgentemente. Após identificar as partes interessadas, com as informações coletadas através das visitas e com os resultados obtidos na análise das raízes causais obtiveram-se então os dados relevantes e o laudo técnico e de recomendações foi gerado, como pode ser observado no apêndice B.

\section{CONSIDERAÇÕES FINAIS}

As metodologias citadas foram adaptadas para o contexto brasileiro através de um estudo de caso em um edifício, que teve como foco investigar as possíveis causas das manifestações patológicas existentes nele, todas as informações pertinentes estão contidas no laudo técnico que foi gerado e se encontra no apêndice B.

Após a aplicação da metodologia de investigação patológica concluiu-se que houve segregação do concreto na base dos pilares acarretando em ninhos de concretagem devido ao excesso de agregados, problema este que pode ter sido ainda mais agravado devido a possíveis erros durante o transporte e lançamento do concreto.

Além disto, devido ao erro na dosagem do traço, não ocorreu o empacotamento correto dos agregados graúdos, e desta forma, o resultado no estado endurecido não foi o esperado. Houve também, a má disposição dos estribos e o cobrimento das vigas foi executado sem o mínimo exigido pela norma atual, desta maneira, a armadura ficou exposta a 
agentes agressivos. A sugestão de como resolver estes problemas se encontra no item Recomendações dentro do Laudo Técnico, apêndice B.

De acordo com estes resultados, percebeu-se que esta nova metodologia proposta atende as necessidades dos engenheiros em relação à facilidade de se encontrar as origens das falhas, pois as etapas de investigação orientam detalhadamente o profissional, diferente da metodologia nacional existente (figura 1) que faz uma análise geral. Comprovou-se também que reunir os princípios e metodologias da análise forense, pode auxiliar o engenheiro a garantir que a investigação patológica foi realizada da maneira mais correta possível, uma vez que, estas técnicas fornecem certo grau de confiança de que todas as hipóteses prováveis da causa foram pensadas.

\section{REFERÊNCIAS}

ASSOCIAÇÃO BRASILEIRA DE NORMAS TÉCNICAS. NBR 14653-1: Avaliação de bens: parte 1: procedimentos gerais. Rio de Janeiro. 2019.

. NBR 15575-1: Edificações habitacionais: desempenho: parte 1: requisitos gerais. Rio de Janeiro. 2013.

Janeiro. 2012

NBR 5674: Manutenção de edificações: requisitos para o sistema de gestão de manutenção. Rio de

. NBR 6118: Projeto de estrutura de concreto: procedimento. Rio de Janeiro. 1978.

. NBR 6118: Projeto de estrutura de concreto: procedimento. Rio de Janeiro. 2007.

. NBR 6118: Projeto de estrutura de concreto: procedimento. Rio de Janeiro. 2014.

. NBR 8681: Ações e segurança nas estruturas: procedimento. Rio de Janeiro. 2004.

DEUTSCH, Simone Feigelson. Perícias de engenharia: a apuração dos fatos. 2. ed. São Paulo: LEUD, 2013. 222p.

ENAMI, Rodrigo Mazia. Engenharia forense aplicada às obras urbanas. 131f. (Dissertação de Pós-graduação em Engenharia Urbana). Maringá, UEM, 2010.2 Disponível $<$ http://www.peu.uem.br/DISSERTAO_RodrigoMaziaEnami2.pdf>. Acesso em: 15 Abr. 2019.

FERreIRA, Aurélio Buarque de Holanda. Dicionário Aurélio da Língua Portuguesa. 5. ed. Positivo, Brasil: 2014. $2272 p$.

HELENE, Paulo R. L. Manual para reparo reforço e proteção de estruturas de concreto. 6. ed. Pini, São Paulo: 2002. 218p.

KARDON, Joshua B. Guidelines for forensic engineering practice. 2. ed. United States of America: ASCE, 2012.

MARCONI, Marina de A.; LAKATOS, Eva Maria. Técnicas de pesquisa: pesquisa, planejamento e execução de pesquisas, amostragens e técnicas de pesquisa elaboração, análise e interpretação de dados. 5. ed. Revisada e ampliada. São Paulo: Atlas, 2002.

NOON, Randall. Forensic engineering investigation. 1. ed. Florida: CRC Press, 2001. 488p.

STIMSON, William A.. Forensic systems engineering: evaluating operations by discovery. 1. ed. Hoboken: WILEY, 2018. 340p.

TERWEL, Karel; SCHUURMAN, Michiel; LOEVE, Arjo. Improving reliability in forensic engineering: the Delft approach. Proceedings of the Institution of Civil Engineers - forensic engineering. v. 171, n. 3, ago./2018. Disponível em: <https://doi.org/10.1680/jfoen.18.00006>. Acesso em 08 mar. 2019.

TERWEL, Karel C. Structural safety: study into critical factors in the design and construction process. 256f. (Tese de $\mathrm{PhD}$ em segurança estrutural na engenharia civil). Netherlands, Delft University of Technology, 2014. Disponível em: $<$ https://repository.tudelft.nl/islandora/object/uuid:c8a11e06-6ea8-49e7-b18c $>$. Acesso em 08 mar. 2019. 


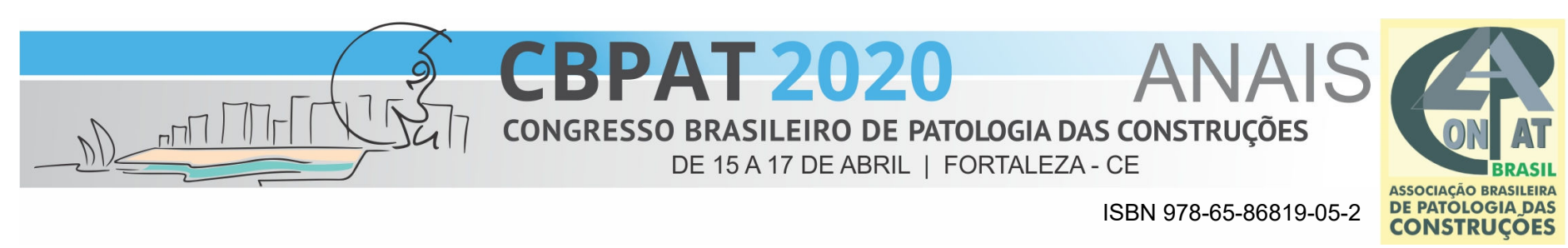

APÊNDICE A

\begin{tabular}{|c|c|c|c|c|}
\hline Falha & Caules causais & $\begin{array}{l}\text { Raízes } \\
\text { causais }\end{array}$ & Hipóteses geradas & Motivo Lógico \\
\hline \multirow{4}{*}{ Produto } & \multirow{3}{*}{ Estrutura } & Material & $\begin{array}{l}\text { Problema relacionado a } \\
\text { montagem dos estribos. }\end{array}$ & $\begin{array}{l}\text { Falta de estribos e a má disposição do seu espaçamento pode causar diversos } \\
\text { problemas estruturais. Ver figura } 4,5 \text { e } 6 .\end{array}$ \\
\hline & & Pureza & Impureza nos agregados. & $\begin{array}{l}\text { Na década de } 80 \text { na cidade de Araguaína/TO o controle tecnológico na produção do } \\
\text { concreto era praticamente inexistente. }\end{array}$ \\
\hline & & $\begin{array}{l}\text { Problemas } \\
\text { Externos }\end{array}$ & Não se aplica neste caso. & Raiz que leva em consideração o ambiente na época da execução da construção \\
\hline & Ergonomia & Usável & $\begin{array}{l}\text { Falta de um manual de } \\
\text { como usar e realizar as } \\
\text { manutenções das } \\
\text { edificações. }\end{array}$ & $\begin{array}{l}\text { A ABNT (NBR 15575: 2013) recomenda que o construtor crie um manual de como } \\
\text { usar e realizar as manutenções no edifício da melhor forma possível. }\end{array}$ \\
\hline \multirow{3}{*}{ Instrução } & \multirow{3}{*}{$\begin{array}{l}\text { Normas e } \\
\text { Regulamentos }\end{array}$} & Aplicável & Não se aplica neste caso. & Para esta raiz é necessário ter acesso ao projeto original. \\
\hline & & Válido & $\begin{array}{c}\text { Problemas com o } \\
\text { cobrimento devido à falta } \\
\text { de especificações técnicas } \\
\text { na época. }\end{array}$ & $\begin{array}{c}\text { Quando o prédio foi construído em } 1987 \text { a norma vigente a respeito de concreto } \\
\text { armado, ABNT (NBR 6118:1978), não especificava valores mínimos de } \\
\text { cobrimento. }\end{array}$ \\
\hline & & Disponível & $\begin{array}{c}\text { Concreto de baixa } \\
\text { qualidade devido à falta de } \\
\text { informações a esse respeito } \\
\text { na norma disponível ABNT } \\
\text { (NBR 6118:1978). }\end{array}$ & $\begin{array}{l}\text { Na norma existente, ABNT (NBR 6118:1978), não era especificado a relação } \\
\text { água/cimento ideal para a resistência necessária. De acordo com ela a quantidade de } \\
\text { água a ser usada era "a mínima compatível com a trabalhabilidade necessária". }\end{array}$ \\
\hline \multirow[b]{2}{*}{ Execução } & \multirow{2}{*}{$\begin{array}{l}\text { Conhecimento } \\
\text { Protocolo } \\
\text { Habilidade }\end{array}$} & Habilitado & $\begin{array}{l}\text { Reparos sem responsáveis } \\
\text { técnicos e sem projeto. }\end{array}$ & $\begin{array}{l}\text { Nessa edificação foram realizadas manutenções com cunho apenas estético. } \\
\text { Ver figura } 6 .\end{array}$ \\
\hline & & $\begin{array}{l}\text { Escolha } \\
\text { Correta }\end{array}$ & $\begin{array}{l}\text { Erro ao escolher a } \\
\text { quantidade de agregado a } \\
\text { ser colocado na dosagem. }\end{array}$ & $\begin{array}{l}\text { Como mostra à figura } 4 \text { a quantidade de agregado é muito grande. O que pode } \\
\text { causar ninhos de concretagem e posterior desagregamento da placa de concreto. }\end{array}$ \\
\hline
\end{tabular}




\section{APÊNDICE B}

\section{LAUDO TÉCNICO}

O presente Laudo Técnico tem como objetivo atender a solicitação de parecer técnico, a vistoria foi motivada porque a comunidade notou o desplacamento de concreto em alguns pilares e vigas. Referente ao prédio situado na Rua Humberto de Campos, esquina com a Avenida Primeiro de Janeiro, $\mathrm{n}^{0}$ 508, bairro São João, na cidade de AraguaínaTO.

\section{DESCRIÇÃO DO PRÉDIO}

O prédio em questão têm $1920,3 \mathrm{~m}^{2}$ de área construída, conta com 4 blocos e mais de 50 salas, além de banheiros, depósitos, copas, cozinhas, salas de espera e um salão para atendimento ao público. É um prédio com cerca de 32 anos, com fachadas, pilares e vigas bem danificados, em termo da falta de cobrimento da armadura. No dia da nossa visita ( 02 de outubro de 2019) as fotos contidas no corpo do artigo foram tiradas. Conforme se pode verificar nas fotos e nas considerais finais do artigo supracidado, parte do prédio se encontra em péssimo estado de conservação.

\section{DESCRIÇÃO DA VISTORIA}

Foi realizada uma vistoria visual numa quarta-feira, dia 02 de outubro do corrente ano. Com base na vistoria visual pôde-se observar diversas patologias na referida edificação.

\section{CONDIÇÕES GERAIS DA EDIFICAÇÃO E AVARIAS A SEREM REPARADAS}

O conjunto de prédio possui patologias nas bases dos pilares, em que é visível presença de ninhos de concretagem ocorridos devido ao erro na dosagem do concreto; há locais em que o cobrimento não foi executado com a espessura mínima recomendada por norma e a armadura de elementos estruturais está exposta, além da perda de seção de concreto.

Percebe-se também que os reparos executados ao longo dos anos, possuíam apenas cunho estético e sem responsável técnico, já que foi possível notar que em vigas que perderam significativa seção de concreto a armadura exposta foi apenas repintada.

\section{RECOMENDAÇÕES}

Com base nesta vistoria visual e nos registros fotográficos presentes no artigo, pôde-se observar diversas manifestações patológicas na referida edificação, que pela gravidade constatada, orienta-se que os responsáveis pelo prédio contratem um engenheiro civil que possa reparar os diversos problemas estruturais apontados neste laudo. Nestes casos de reforço estrutural é recomendado que seja aplicada a maioria dos critérios estabelecidos para o dimensionamento de estruturas novas. Na edificação estudada é necessário fazer a remoção do concreto afetado, limpar as barras de aço aparentes com jatemento de areia e reconstituir a seção original, corrigida pelo cobrimento mínimo em relação a classe de agressividade ambiental que hoje é exigido pelo ABNT (NBR 6118: 2014).

Araguaína, 18 de novembro de 2019. Emylle Lopes e Geovana Barreto. Acadêmicas de Engenharia Civil. 